\title{
BIOLOGY
}

\section{РОЛЬ КОМПЕНСАТОРНЫХ МЕХАНИЗМОВ СЕТЧАТКИ В УСЛОВИЯХ ПИГМЕНТНОЙ ДИСТРОФИИ}

\author{
Н. М. Рзаева, А. И. Дмитренко, А. Н. Нуруллаева, Э. Н. Панахова, М. Х. Ализаде \\ Институт физиологии им. А. И. Караева Наџиональной Академии Наук Азербайджана, \\ Азербайджан
}

DOI: https://doi.org/10.31435/rsglobal_ws/31102019/6714

\section{ARTICLE INFO}

Received: 11 August 2019

Accepted: 16 October 2019

Published: 31 October 2019

\section{KEYWORDS}

retinogramm, pigmentary dystrophy, $\mathrm{a}-\mathrm{b}$-components,

PD,

Stem Cell.

\begin{abstract}
Researching some aspects of functioning retina performance in conditions of pigmentary dystrophy (PD) will allow revealing a number of features regarding its existence and sequence of restoration both as respector and neural systems.Research objecture. To investigate dynamics of formation of electroretinogram (ERG) in conditions of retina PD. Materials and methods. Chronic experiments were conducted on awake rabbits for a month in the norm and condition of PD. Results. The received results testily that formation $\mathrm{a}-$ and $\mathrm{b}-\mathrm{ERG}$ components in condition of PD was ambiguous. Amplitudes of a - waves higher $(76,4 \%)$ than those of $b-$ waves $(44,4 \%)$. Conclusion. Partial recovery of ERG components is a result of the inclusion of retina backup mechanisms capable of withstanding pathological process and restoring vision.
\end{abstract}

Citation: Н. М. Рзаева, А. И. Дмитренко, А. Н. Нуруллаева, Э. Н. Панахова, М. Х. Ализаде. (2019) The Role Compensatory Mechanisms of Retina in Conditions of Pigmentary Dystrophy. World Science. 10(50), Vol.1. doi: 10.31435/rsglobal_ws/31102019/6714

Copyright: (C) 2019 Н. М. Рзаева, А. И. Дмитренко, А. Н. Нуруллаева, Э. Н. Панахова, М. Х. Ализаде. This is an open-access article distributed under the terms of the Creative Commons Attribution License (CC BY). The use, distribution or reproduction in other forums is permitted, provided the original author(s) or licensor are credited and that the original publication in this journal is cited, in accordance with accepted academic practice. No use, distribution or reproduction is permitted which does not comply with these terms.

Раскрытие некоторых интимных механизмов функционирования периферического отдела зрительной системы - сетчатки- в условиях пигментной дистрофии позволит выявить некоторые особенности этой весьма сложной структуры, в функцию которой входит первичная обработка зрительной перцепции.

Чтобы изучить различные заболевания сетчатки необходимо воспроизводить их. Проведение электрофизиологических, гистологических, биохимических, гистохимических и др. методов исследований на людях, страдающих глазными болезнями, практически невозможно. Для решения этой проблемы создают их экспериментально на животных, что в дальнейшем позволит дополнить сведения о причинах заболевания глаз у человека

Для объяснения патогенеза пигментной дегенерации сетчатки проводились исследования ретинопатий, вызванных введением в общее кровяное русло токсических веществ, действующих на сетчатку $[1,2,3]$ Наиболее сходными с пигментным ретинитом оказались дегенерации сетчатки, вызванные солями йода и фенотиазина.

Bпервые W.K.Noell [4] обратил внимание на значительное сходство монойодуксусной кислоты (МИУК) с одной стороны и проявлениями пигментного ретинита человека - с другой. В работах и других авторов [5,6] было показано, что электрический ответ сетчатки изменялся довольно быстро после инъекции монойодацетата и исчезал полностью в течение первых пяти минут почти у всех экспериментальных животных.

В работах Абдуллаев Г.Б. и др [7], Рзаевой Н.М., Дмитренко А.И.[5] было показано, что в условиях пигментной дистрофии сетчатки поражаются в первую очередь и в большей степени 
наружные сегменты фоторецепторов, формирующие ранний рецепторный потенциал, который является одним из самых ранних показателей развития ПД. При этом порог формирования его увеличивался с 1,5-2 Дж до 5-7 Дж, а с увеличением сроков развития патологии, в процесс вовлекались уже как внутренние сегменты фоторецепторов, так и нейрональные элементы сетчатки. При этом уменьшались амплитудные параметры a- и b- компонентов ЭРГ, осцилляторные потенциалы, а также экстрапотенциалы [5].

Вопрос о существовании компенсаторных процессов в сетчатке является весьма актуальным.

Использование в качестве теста a- и b компонентов ЭРГ позволит выявить наличие компенсаторных механизмов сетчатки, которые в условиях патологии способны в какой-то степени восстанавливает еe функцию. Полученные результаты, возможно, дадут дополнительный материал для клинической офтальмологии в отношении оценки функционального состояния сетчатки в связи с конкретными проявлениями ее структурных нарушений. Решение этого вопроса может иметь отношение к расшифровке механизма существования компенсаторных процессов в зрительной системе при нарушении ее периферического отдела.

Задачей настоящих исследований - проследить в течение месяца динамику формирования a- и b-компонентов ЭРГ в условиях пигментной дистрофии сетчатки и выявить существование компенсаторных процессов в ней.

\section{Материалы и методы.}

Опыты проводились в хронических условиях экспериментов на бодрствующих кроликах. Исследовалась ЭРГ в контроле и при пигментной дистрофии сетчатки в течение месяца. Для регистрации ЭРГ использовались интенсивности световых стимулов 0,016 Дж; 0,068Дж; 0,45Дж; 1,4Дж. Для создания ПД в ушную вену вводили раствор МИУК из расчета 25мг/кг. В работе представлены средние статистические данные амплитудных параметров а- и b -компонентов ЭРГ, как в абсолютных величинах $(\mathrm{m \kappa} \mathrm{V})$, так и в процентном отношении к контролю. Проводились не только электрофизиологические, но и гистологические исследования.

\section{Результаты и обсуждение.}

Установлено, что в условиях ПД сетчатки наблюдалось выраженное подавление а- и b компонентов ЭРГ. Так, в контроле в диапазоне исследуемых интенсивностей световых стимулов 0,016 Дж, 0,068 Дж, 0,45 Дж и 1,4Дж амплитуда а-волны в среднем составляла соответственно $46,6 \mathrm{m \kappa} \mathrm{V}, 94,8 \mathrm{m \kappa V}, 106,2 \mathrm{m \kappa V}$. Следует отметить, что при интенсивности света 0,016Дж, в наших экспериментах а-волна не регистрировалась . Что касается b-волны, то в контроле амплитуда ее в среднем составляла соответственно $159.4 \mathrm{m \kappa V}, 162,5 \mathrm{m \kappa V}, 211,2 \mathrm{m \kappa V}$ и $222,3 \mathrm{m \kappa V}$. (рис.4)

На ранних этапах развития ПД выявлено, что после введения МИУК развивалась характерная патология (рис.1,2,3), которая проявлялась в резком снижении амплитудных параметров исследуемых компонентов ЭРГ на световые стимулы различной интенсивности.

Так, на 5 день наблюдалось весьма выраженное уменьшение a - и b-волн. При интенсивности света 0,016 Дж ЭРГ не регистрировалась, а при последующих - 0,068Дж; 0,45 Дж и 1,4 Дж а-волна составляла соответственно $12,5 \pm 2 \mathrm{m \kappa V}(30,8 \%) ; 22,3 \pm 2 \mathrm{m \kappa V}(30,5 \%)$ и

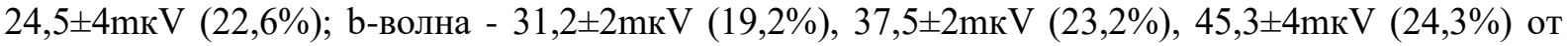
контроль - $100 \%$ (рис.4).

Такое резкое уменьшение амплитудных параметров компонентов

ЭРГ, по-видимому, свидетельствует о том, что нарушен самый первичный физикохимический механизм, связанный с фотолизом родопсина в дисках наружных сегментов фоторецепторов (9). По данным W.K.Noell [10] при дистрофии сетчатки, вызванной введением МИУК, патологический процесс в первую очередь развивается в пигментном эпителии и в большей степени поражается скотопическая система. Об этом свидетельствуют данные [8], полученные при исследовании в условиях патологии изменений суммарной амплитуды ЭРГ, вызванной активности в верхних буграх четверохолмия (ВБЧ) и зрительной коре (ЗК). Так, амплитуда ЭРГ по сравнению с контролем подавлялась на 36-48\%, вызванные потенциалы (ВП) ВБЧ - на $85-90 \%$, а ВП ЗК всего лишь на 25-35\%. Этот факт указывает на то, что в отличии от ЗК и сетчатки, в генезе которых принимают участие как скотопическая так и фотопическая системы, ВБЧ имеют вход только от скотопической системы. Следовательно, при патологии сетчатки в первую очередь и в большей степени страдает именно ее палочковый аппарат. На 14 день отмечались некоторые сдвиги в функциональном состоянии сетчатки, о чем свидетельствуют возросшие амплитудные параметры компонентов ЭРГ. Так, при интенсивностях света 0,016 Дж, 0,068Дж, 0,45Дж и 1,4Дж а-волна составляла соответственно 


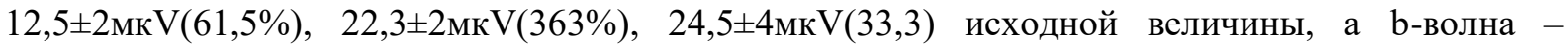
$56,3 \pm 3 \mathrm{m \kappa V}(36 \%), 62,5 \pm 5 \mathrm{м \kappa} \mathrm{V}(38,4 \%), 62,5 \pm 4 \mathrm{m \kappa V},(29,6 \%), 63,5 \pm 6 \mathrm{m \kappa} \mathrm{V}(32,9 \%)$.

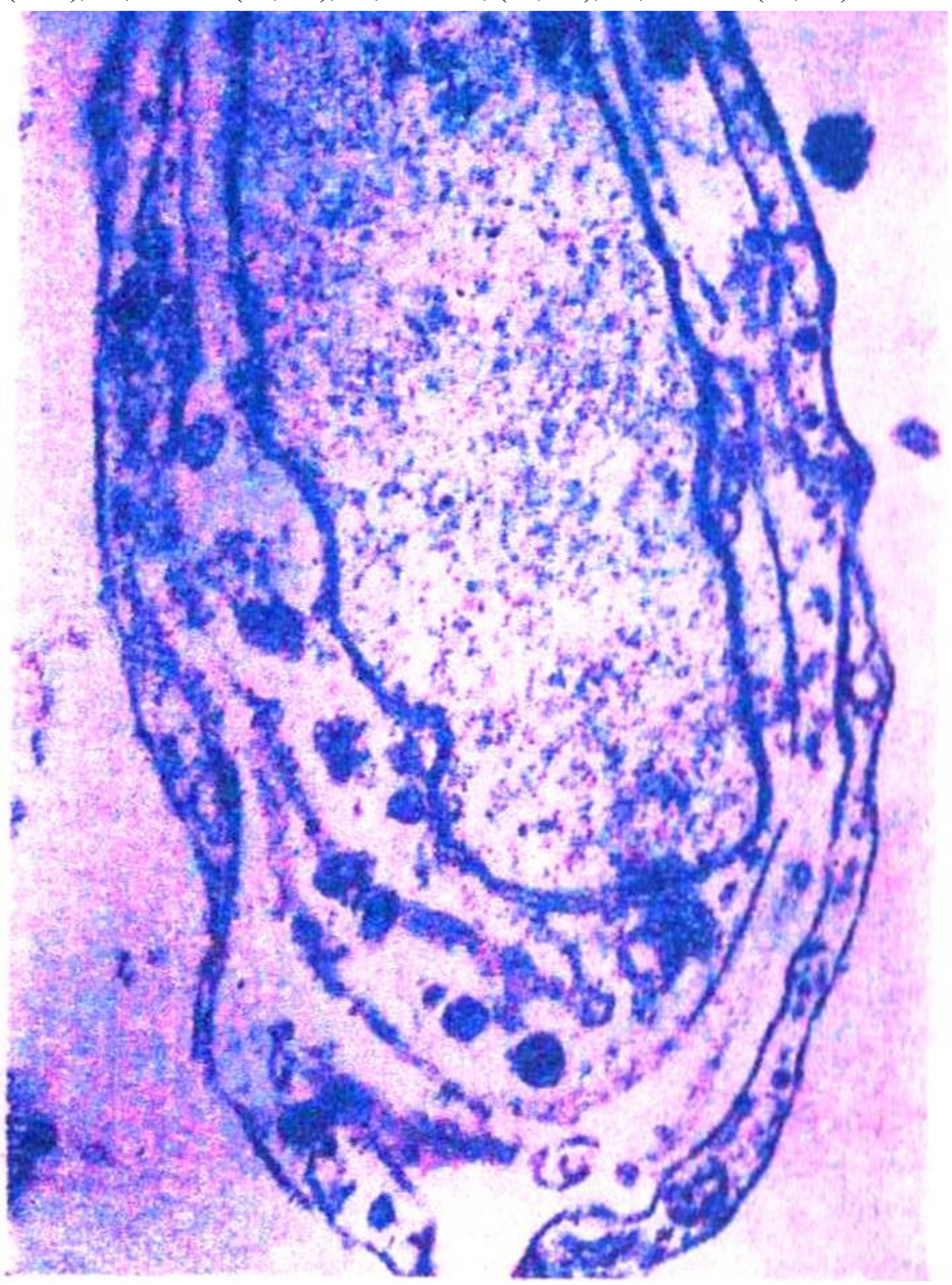

Рис.1 А. Нормальная структура пигментной клетки сетчатой оболочки.

Прирост амплитудных параметров а- и $\mathrm{b}$-компонентов ЭРГ свидетельствует о положительной тенденции, которая сохранялась на протяжении всего последующего периода.

Так, на 27 день а-волна увеличивалась и ее амплитуда при тех же интенсивностях уже составляла соответственно $31,2 \pm 2 \mathrm{M \kappa V}(78,8 \%), 43 \pm 2 \mathrm{MKV}(63,6 \%), 75,2 \pm 3 \mathrm{M \kappa} \mathrm{V}(70,5 \%)$. При этом амплитуда b-волны- $62,5 \pm 1,5 \mathrm{m \kappa V}(32,9 \%), 58,8 \pm 2 \mathrm{m \kappa V}(34,9 \%), 68,8 \pm 3 \mathrm{мкV}(32,2 \%), 62,5 \pm 5 \mathrm{m \kappa V}$. На 31 день при тех же интенсивностях света а-волна составляла $31,2 \pm 2 \mathrm{M \kappa V}(76,8 \%)$,

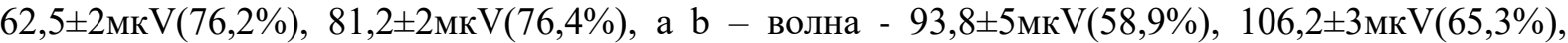
$87,5 \pm 4 \mathrm{мкV}(41,4 \%), 100,8 \pm 2 \mathrm{м \kappa V}(44,4 \%)$.

Таким образом, исследуя в течение месяца формирование a- и b- компонентов ЭРГ в условиях ПД сетчатки, было выявлено выраженное увеличение амплитуды а-волны. Что касается b-волны, то она оставалась значительно меньше контрольной величины.

Обсуждение. Из анализа полученных результатов с учетом литературных данных следует, что сетчатка располагает нервными элементами, которые обладают удивительной способностью восстанавливать не только клеточные элементы, но и ее функцию. 

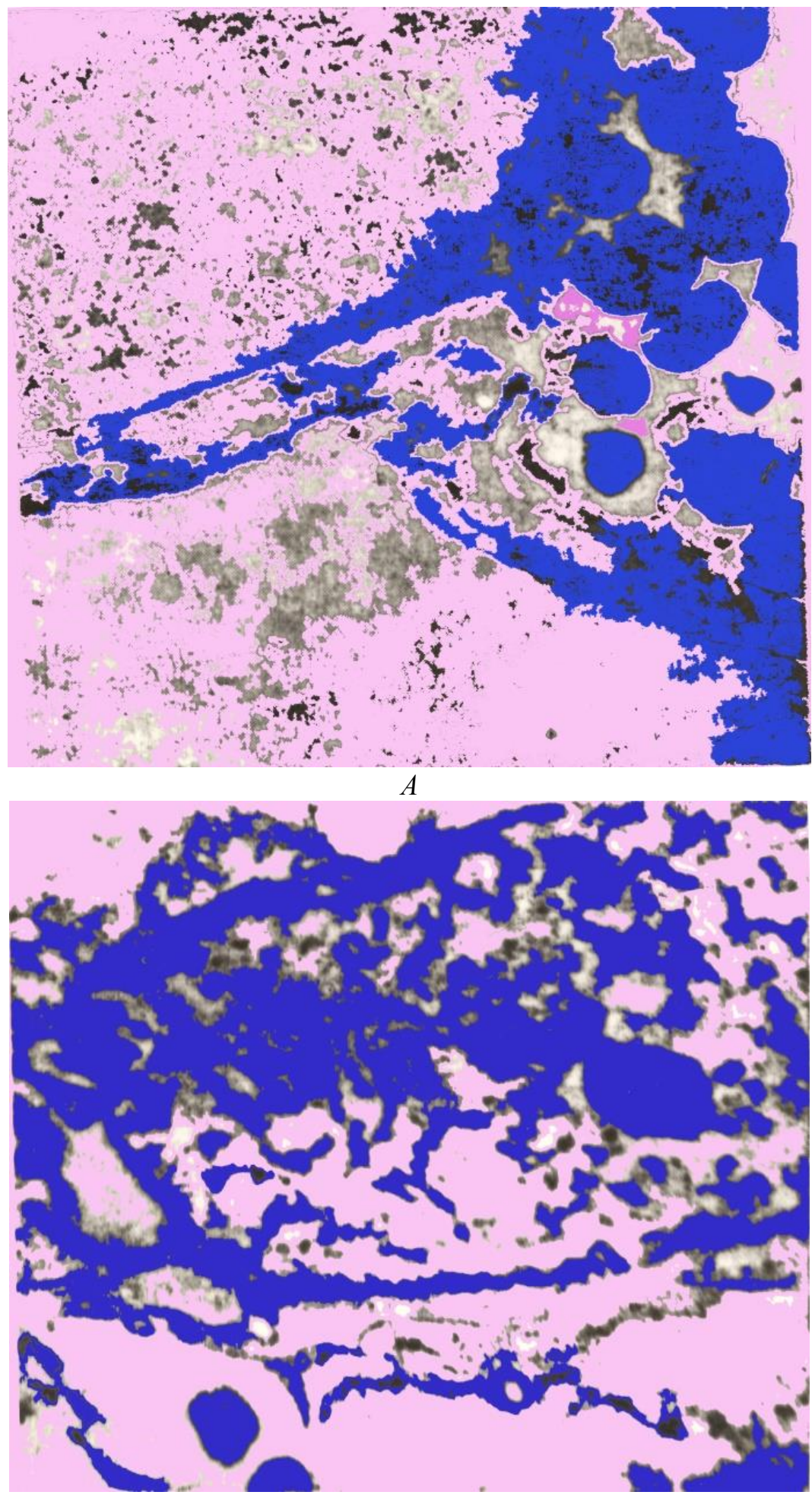

Б

Рис.2. А-часть пигментной клетки, скопление пигмента в иитоплазме, набухание цичтоплазматической мембраны. Увел.х115000.

$Б$ - деструктивные изменения в ядре пигментной клетки. Проникновение пигмента в ядро.

\section{Увел.х50000.}

Наиболее важное ключевое значение в механизме восстановления либо генерации новых нейрональных элементов [11] в различных структурах мозга, имеет нейротрофический фактор, т.е. фактор роста нервов (NGF), являющийся «началом начал». Первостепенную роль при этом выполняют нейротрофины, участвующие в реабилитации структуры и ее функции, активизирующие тем самым, естественные компенсаторные механизмы в поврежденных клетках сетчатки. Из этого следует, что восстановление а-волны ЭРГ, в генезе которой принимают участие фоторецепторы и 
горизонтальные клетки [9], по-видимому, связано с пигментным эпителием, который обладает уникальной особенностью к самоорганизации и трансдифференцированию, что позволяет ему осуществлять воспроизведение клеточных образований в том числе и фоторецепторов [12].
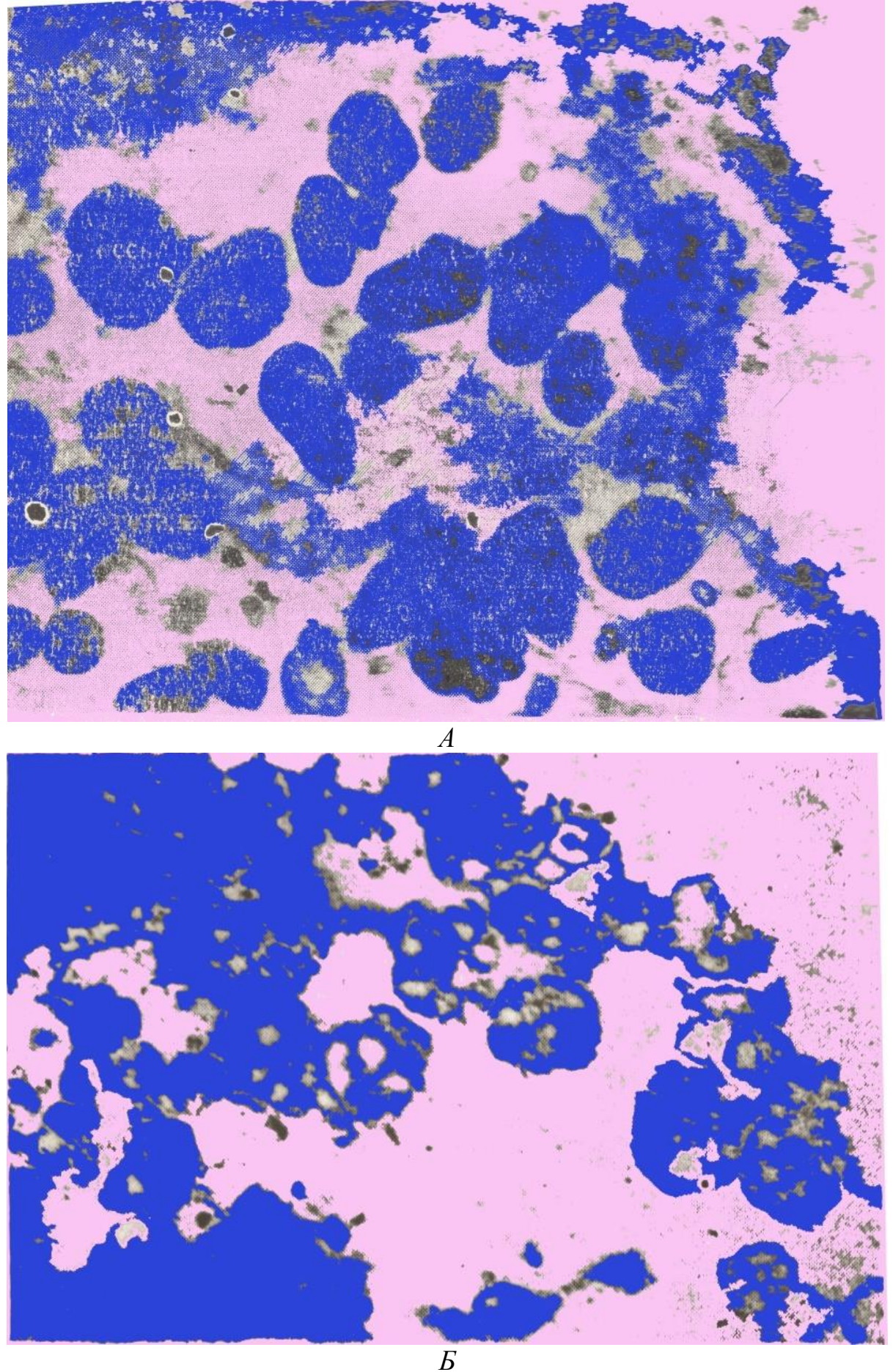

Рис. 3. А-скопление пигмента в межклеточном пространстве среды и разрушенных элементов клетки. Увел.х100000.

Б一клетки пигментного эпителия в различной стадии дистрофии-в одних пигмент исчезает, а в других накапливается. Увел.х300.

Весьма существенный интерес представляют исследования, проведенные на лягушках G.V. Lopashov и O.G. Stroeva [13]: удалялись все слои сетчатки кроме неповрежденного пигментного эпителия. После аллогенной трансплантации в место дефекта тканей глаза мелкого кусочка сетчатки, взятого у головастика, пигментный эпителий полностью восстанавливал зрительную функцию. 

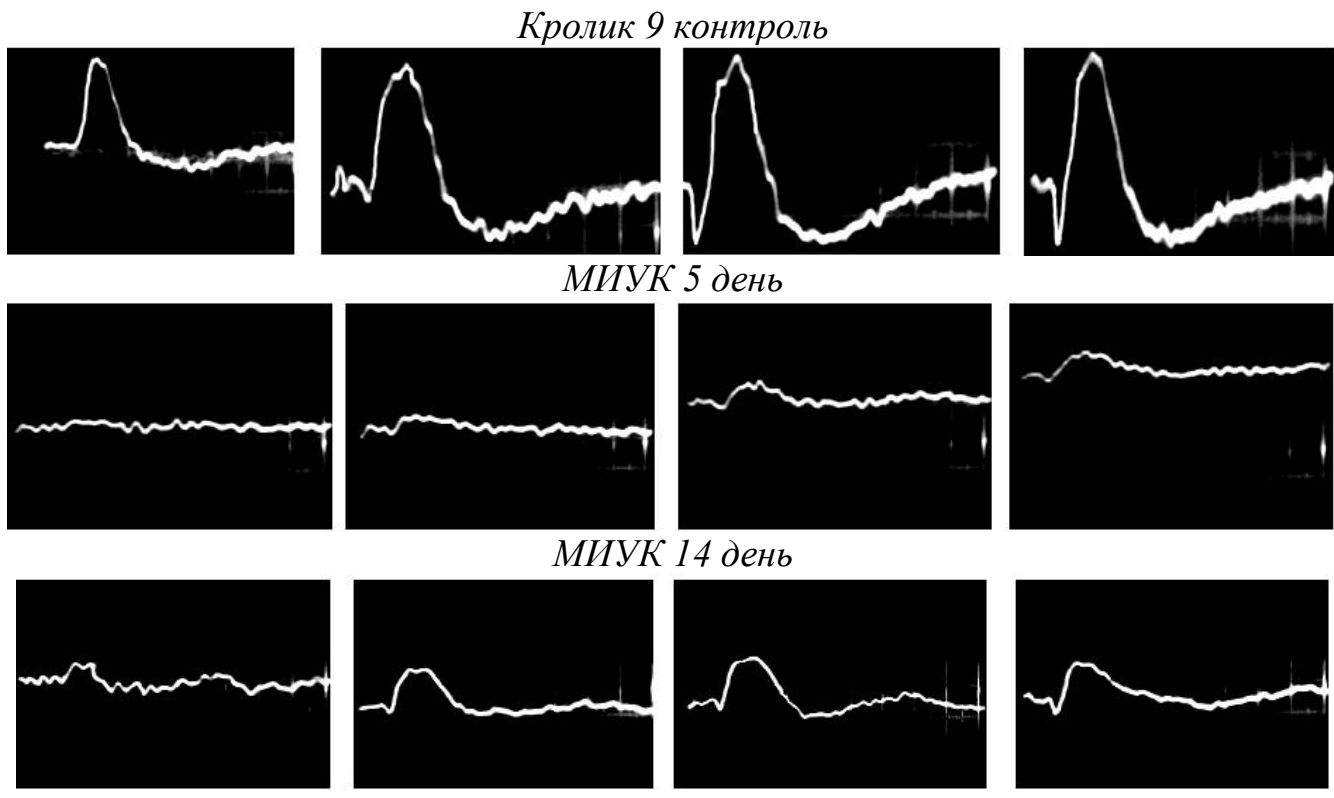

МИУК 27 день
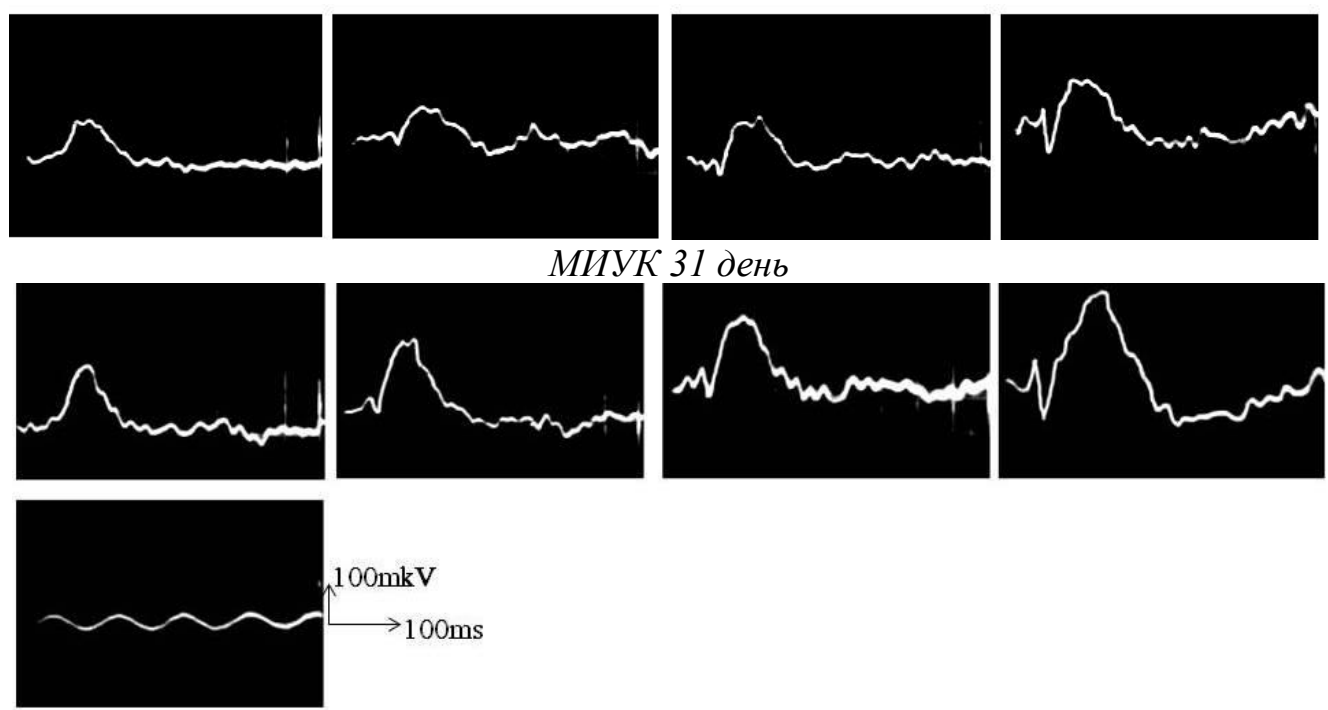

Рис.4. Динамика формирования $a-$ и $b$-компонентов ЭРГ при пигментной дистрофии сетчатки. Цифры - дни регистрачии ЭРГ при ПД сетчатки. Калибровка - 50мкв, 50мс.

Исследованиями Salero E. et al. [14] было показано, что клетки пигментного эпителия сетчатки могут быть хорошим ресурсом для заменительной терапии заболеваний глаз таких, как возрастная макулярная дегенерация и болезнь Штаргардта.

Нельзя исключить и тот факт, что в процессе восстановления функции сетчатки немаловажное значение имеют и мюллеровские клетки (МК), которые являются преобладающими клетками и проходят через все слои сетчатки в виде стержня. Их ядра расположены на уровне биполярных клеток, а отростки достигают наружной и внутренней пограничных мембран. Своими аксонами МК окружают нейроны сетчатки и их дендриты. Так, S.Blackshow et al. [15] на основании экспериментальных данных показали, что МК способны дать начало развитию различных элементов сетчатки. Авторы установили, что после острого нейротаксического повреждения в сетчатке млекопитающих in vivo MК дифференцируются и производят в ней различные нейроны.

Из этих фактов, следует что частичное восстановление b-волны ЭРГ, в генезе которой принимает участие слой нейрональных элементов сетчатки, связано с усилением активности МК. Согласно литературным данным, нельзя исключить и участия в этом процессе пигментного эпителия и, возможно, других клеточных элементов внутреннего ядерного слоя сетчатки.

Таким образом, нарушение нормального функционирования сетчатки в условиях патологии связано с весьма сложными процессами, протекающими в ней $[16,17]$. В то же время 
динамика частичного восстановления компонентов ЭРГ в эксперименте свидетельствует об активизации в сетчатке компенсаторных процессов, Результатом этого является тот факт, что в патологический процесс включаются ее резервные механизмы сетчатки способные в какой-то степени противостоять ему процессам и восстанавливать зрение.

Детальное изучение компенсаторных механизмов сетчатки позволит расширить и углубить существующие представления о клеточной трансформации роста, что приведет к более глубокому и всестороннему пониманию развития различных форм патологии сетчатки.

\section{Выводы.}

1. Выявлено существование компенсаторных процессов в сетчатке, обусловливающих частичное восстановление a- и b-компонентов ЭРГ в условиях пигментной дистрофии.

2. Динамика восстановления амплитудных параметров компонентов ЭРГ в течение месяца неоднозначна: а-волна восстанавливалась до 76,4\%, b-волна до 44,4\%.

3. Активность компенсаторных процессов в сетчатке в большей степени выражена в пигментном эпителии, чем в нейрональном слое.

\section{ЛИТЕРАТУРА}

1. Asakava K., Ishikawa H., Uga S. and etc,. Histopathological Changes of İnner Retina. Optic Disc and optic Nerve in Rabbit üith Advanced Retinis Pigmentosa. Neuroophthalmology 2016; 40 (6): 296-291

2. Hirota R., Kondo M., Ueno S., Sakai T., Koyasu T., Terasaki H., Photoreceptor and post-photoreceptoral contributions to photopic ERG a-wave in rhodopsin P347L transgenic rabbits. Invest. Ophthalmol. Vis.Sci.2012: 53(3) P.1467-72

3. Cytoprotective Effects of a NoveiNrt2 Activator, RS9, in Rhadopsin Pro 347 Leu Rabbits. 2016, 41(8): 1123-1126

4. $\quad$ Noell W.K. The effect of iodeacetate on the vertebrate retina. //J.Cell Comp.Physiol. 1951; 37: 1: $288-307$. doi.org/10.1002/jcp.1030370209

5. Мирюсифова Х.М., Мамедов З.Г. Сравнительный анализ влияния электрической стимуляции различных структур головного мозга на восстановление наружных слоев сетчатки в условиях ретинальной дистрофии./М., Журн. Естественные итехнические науки.2013.№4,т.66.c.108-112.

6. Бабаев Х.Ф., Шукюрова П. А. Экспериментальное исследование действия шафрана посевного (Crocus sativus L.) при таксическом поражении сетчатки. Журн.”Актуальные проблемы гуманитарных и естественных наук”.М.2016.№7.c.28-35.

7. Абдуллаев Г.Б., Эфендиев Н.М., Гаджиева Н.А., Гасанов Г.Г., Несруллаева Г.М., МеликАсланова П.С., Панахова Э.Н. Изучение влияния селенсодержащих пищевых экстрактов на зрительную функцию при дистрофии сетчатки.// Матер второй научн.конф. “Селен в биологии, "Баку, Из-во“ЭЛМ”. 1976; 14-23.

8. Рзаева Н., Дмитренко А.И. Гипоталамус и зрение. Нейрофизиологические особенности функционирования зрительной системы. Германия. LAP LAMBERT Academik Publishing. $2012 ; 317$.

9. Рзаева Н.М. Нейрофизиологические особенности некоторых аспектов функционирования зрительной системы. Баку.2009.175 C

10. Noell W.K. Azide-sensitive Potential Difference Across the eye-Bulb. American J.Physiology.1952; 170: 1: 217-238.

11. Cohen S. Nobel lecture. Epidermal growth factor.// Bioscience Reports.1986; 6(12): 1017-1028. doi.org/10.1007/bf01141022

12. Вит В.В. Роль пигментного эпителия в жизнедеятельности сетчатки.// Мир офтальмологии. 2012

13. Lopashov and O.G Stroeva. Morphogenesis of the Vertebrate Eye.// Adv. in Morphogenesis. 1961; 1:231377 doi.org/10.1016/b978-1-4831-9948-1.50012-7

14. Salero E., Blenkinsop T.A., Corneo B.et al..Adult Human RPE Can Be Activated into a Mulltipotent Stem Cell that Prooduces Masenchymal Rzayeva N.M, Dmitrenko A.I. Gipotalamus and sight. Neurophysiological features of functioning of visual sys-tem. Germany. LAP LAMBERT Academik Publishing. 2012; 317.

15. Blaskshow S.et al., Genomic Analysis of Mouse Retinal Development.// J.PLOS.Biology.2004; 2: 1411-1431

16. Новохатский А.С..Монологи и диалоги по нейроофтальмологии и клинической физиологии зрения. //Луганск. 2008; 27

17. Горбунов А.В., Осокин Ю.Ю. Современная тактика лечения дистрофических заболеваний сетчатки у пациентов старшей возрастной группы. //Успехи геронтологии. М.Медицина.2009; 4 